\title{
The role of personal norms in the choice of mode for commuting
}

\author{
Augustus Ababio-Donkor, Wafaa Saleh \& Achille Fonzone
}

To cite this article: Augustus Ababio-Donkor, Wafaa Saleh \& Achille Fonzone (2020): The role of personal norms in the choice of mode for commuting, Research in Transportation Economics

\begin{abstract}
Research in travel behavioural studies have shown that social forces play a significant role in travel decision making like socio-economic factors. Several studies have tested models with different subjective variables to investigate their effects on travel behaviour. Understanding the influence of social norm and personal norm on travel mode choice preference is essential in promoting sustainable travel, considering the reported importance of these social forces in decision-making. This study draws upon the theories underpinning these sociological constructs and the integrated choice and latent variable (ICLV) framework to develop an ICLV model by incorporating social norm and personal norm as latent variables to investigate their impact on transport mode choice decisions. The results of the ICLV model is consistent with the findings in similar studies and extend the literature in transport mode choice modelling. The results indicate that internalised norms or personal norms have a significant influence on individual behaviour, and positively influence travel behaviour. This strengthens the claim that activated norms and pro-environmental behaviour (PEB) influence overt behaviour by inducing a sense of obligations to act. The results also suggest that individuals with pro-environmental attitude are likely to travel with sustainable travel modes. Thus, reinforcing the importance of sociological and psychological factors in decision-making. Unlike studies involving social norms and personal norms, this research is novel because it applies the ICLV framework to empirically investigate the impact of these sociological constructs on travel mode choice behaviour by incorporating them as latent variables in an ICLV model. The contribution of this study to the literature is that it shows that personal norm has a substantial positive impact on sustainable travel. The impact of this study could be situated in the framework of sustainable transport. The findings are relevant for policymaking, the development of policies meant to create awareness of the consequences of travel behaviour could promote the development of strong personal norms, and consequently influence travel decision making. This can be useful for promoting sustainable travel as the findings shed light on the characteristics of individuals most likely to travel by active modes or PT.
\end{abstract}

\section{Introduction}

One of the most significant challenges confronting urban centres is the increasing motorisation on the roads and its attendant traffic congestions. Cities continue to review, develop, and implement new strategies directed at curbing this situation, yet the trend continues (Transport Scotland, 2018b). Unfortunately, this phenomenon is detrimental not only to the well-being of urban dwellers but the environment as well. Major cities around the world, including Edinburgh, continue to observe this worrying trend (Shan \& John, 2015; TomTom International BV, 2016; Transport Scotland, 2018b), despite the observed "peak car" in some cities (Goodwin \& Dender, 2013; Millard-Ball \& Schipper, 2011) and the conscious efforts to reverse the trend. 
However, transport models developed to understand, explain, and address travel behaviour and the observed trend above have come short of reversing the observed trend. Literature is replete with evidence suggesting that human behaviour, and for that matter travel behaviour, besides economic factors and physical infrastructure, is also shaped by social and cultural forces as well (Ben-akiva \& Bierlaire, 1999; Halonen, 2020; Liu et al., 2017; Manski, 1973; Simon, 1955). Social norms (an ideal form of behaviour to which individuals in a social group conform to) is suggested to significantly sway individual or group behaviour (Cialdini et al., 1999; Cialdini, 2007; Cialdini et al., 1991; Halonen, 2020; Hiselius \& Rosqvist, 2016; Riggs, 2016, 2017). Norms are related to herding behaviour, the effectiveness of which comes from the social penalties or possible reputational damage for non-compliance or the social benefits of conformity (DellaVigna, 2009). Therefore, economic, and physical interventions alone are inadequate to deliver behavioural change and sustainable travel.

There is a substantial amount of literature on the link between travel behaviour and sociological factors ( Ferreira \& Wijngaard, 2019; Aczél \& Markovits-somogyi, 2013; Avineri, 2011, 2012a, 2012b; Avineri et al., 2009; Metcalfe \& Dolan, 2012; Schroeder et al., 1983; Simon, 1982). According to these studies, social norms, activated social norms in the form of personal norms, and pro-environmental attitudes are essential for delivering sustainable behaviour change; specifically, travel behaviour change, as well as influences behavioural intentions and actual behaviour (Bamberg et al., 2007; Belgiawan et al., 2016; Cialdini et al., 1991).

Considering the reported importance of social forces in decision-making, this study explores the impact of norms (social and personal) on the travel behaviour of the population of Edinburgh, Scotland. The primary objective is to understand whether personal norms and social norms are of comparative significance to objective factors (such as income, age, car ownership and walking distance to bus stops) in the choice of transport mode (Schwartz, 1977; Bamberg et al., 2007; Belgiawan et al., 2016; Cialdini et al., 1991; Avineri, 2009a). Unlike studies involving social norms and personal norms, this research is novel because it empirically examines the effect of norms (perceived social norms and personal norm) on travel mode choice behaviour by incorporating them as latent variables in an ICLV model. We estimate and compare an ICLV model and MNL model to assess whether the presence of social norms and personal norm as latent variables improves the power of the choice models and the extent to which both latent variables affect individual observed travel preferences. We analysed a sample size of 500 respondents collected through revealed preference travel survey using postal survey in Edinburgh for this study. We hypothesize that both social norms and personal norms significantly impact travel mode choice preferences. The results are consistent with and contribute to the literature, and also the findings have implications for PT policy design.

The results demonstrate that personal norm or pro-environmental attitudes rather than social norms influence the choice of transport mode. The results also suggest that individuals with proenvironmental attitude are likely to travel with sustainable travel modes. Thus, reinforcing the importance of sociological and psychological factors in decision-making. The findings are relevant for policy-making, the development of policies meant to create awareness of the consequences of travel behaviour could promote the development of strong personal norms, and consequently influence travel decision making.

The paper is structured as follows: We start with the review of relevant literature on the tie between Norms and travel behaviour, followed by the methodology and data collection process. Next, the paper presents a description of the sample data and initial analysis of the indicators for assessing norms. The fifth section covers the model estimation and the framework for 
incorporating the latent variables into the choice model. Finally, we present and discuss the modelling results and give the policy implication of the finding, the limitation of the study and recommendation for future work as well as the conclusion of the study.

\section{Literature Review}

With little variations, several studies on transport choice behaviour suggest that the random utility theory and the utility maximisation theory are not entirely accurate in their prediction of human behaviour (Ben-akiva \& Boccara, 1995; Ben-Akiva et al., 1999; Manski, 1973; Simon, 1955). These traditional models do not consider the heterogeneity of human behaviour, attitudes and preferences (Aczél \& Markovits-somogyi, 2013; Avineri, 2012a; Manski, 1973). Manski (1973) explained that the predictions of some traditional choice models are irrational in themselves. After the pioneering study by Manski (1973), several researchers have explored this subject and have developed choice models that incorporate attitudinal and behavioural variables as latent factors to account for the subjectivity of human behaviour, which was absent in the previous models (Ben-akiva \& Boccara, 1995; Ben-Akiva et al., 2002). Johansson \& Heldt (2006) developed a hybrid choice model with the inclusion of personality and attitudinal variables and concluded that the addition of subjective variables could enhance the power of choice models. Yáñez et al. (2010) also developed hybrid choice models with accessibility, reliability and comfort/safety as latent variables. The authors found the results of their model superior to the traditional models that did not account for the effect of these subjective factors.

Similarly, Belgiawan et al. (2016) studied factors influencing car purchase decision among Indonesian students. The authors constructed five latent constructs: symbolic/affective, arrogance prestige, independence, comfort, and social/environmental care. The study reported that aside the socio-demographic variables, arrogance prestige and independence had a significant impact on car purchase decision (Belgiawan et al., 2016).

Relevant literature in behavioural economics also suggests that norms influence behaviour to a large extent. Norm is a "standard or ideal form of behaviour to which individuals in a social group try to conform" (Burke \& Young, 2011; Mackie et al., 2015). Norm is also suggested to signal appropriate behaviour or acceptable actions by a majority of people. Norm is an omnibus concept that could refer to social norms, legal norms and personal norms. Social norm is informal and describes a subject's belief about what a reference group (those whose expectation matter to a given individual in the situation) does and/or thinks should be done (Mackie et al., 2015).

Schwartz (1977) described social norm as expectations, obligations, and sanctions currently associated with a reference group. Social norms are held in place by the reciprocal expectation and the fear of social penalties by the reference group (Bamberg et al., 2007; Mackie et al., 2015). Legal norms are formal rules governing a reference group; this is backed by laws and are enforceable, while personal norm or personal attitude; on the other hand, refers to individual values and principles.

Personal norm or personal attitude is personalised or internalised social norm (Schwartz, 1977). Unlike social norm, which is externally motivated, personal norm is internally motivated (Schwartz, 1977; Cialdini et al. , 1991; Bamberg et al., 2007; Mackie et al., 2015). Several studies have indicated that personal norm has a significant impact on overt behaviour than social norms (Schwartz, 1977; Cialdini et al., 1991; Bamberg et al., 2007). In a study to evaluate the acceptability of three Travel Demand Management (TDM) schemes meant to reduce car use, Erikssona et al. (2006) investigated the extent to which the TDM measures are perceived to influence the freedom to choose travel mode, and people reduction of car use. It was found that the acceptability of the TDM measures was a function of problem awareness and personal norm. 
Similarly, Zhang et al. (2016) found that the intention to use public transport was influenced by the expectation of important others and activated personal norms. The study also found a weak link between income and public transport use intention. It is suggested that activated personal norms prompt behaviour and the moderating factor of pro-environmental behaviour (PEB) (Ferreira \& Wijngaard, 2019; Schwartz, 1977; Zhang et al., 2016).

Social norms or peer influence and approval from social group is suggested to sustain behaviour, influence travel behaviour and could lead to behaviour change of students (Avineri et al., 2009; Hirshleifer, 1993; Long et al., 2015). In a review of the effectiveness of using social nudges in mobility management campaigns directed at changing travel behaviour, Hiselius \& Rosqvist (2016) reinforced the earlier findings in Cialdini et al. (1991). Hiselius \& Rosqvist (2016) further argued that it is possible to achieve a more sustainable travel behaviour change by focusing on social norms and environmental effects of behaviours. Lind et al. (2015) applied structural equation modelling to investigate the value-belief-norm (VBN) model and examined the relative importance of personal norms and the relationship between personal norms and travel mode choice using data from Norwegian urban dweller. The study found that values, and norms were associated with travel mode choice, and probably also mode use. In support of the assertation that activated personal norms prompt behaviour and the moderating factor of pro-environmental behaviour (PEB) (Ferreira \& Wijngaard, 2019; Schwartz, 1977b; Zhang et al., 2016), Klöckner \& Blöbaum (2010) found that personal norms have a relatively strong impact on habits and usually generated directly prior to a behavioural decision. In a SEM analysis involving, personal norm, behavioural intention and social norms, Han (2014) proposed that creating awareness of the effects of behaviour could have substantial impact on personal norm and behavioural intention.

Whiles investigating the impact of financial incentives and social norm on the willingness to change travel behaviour, Riggs (2017) found social nudges more effective than financial inducement meant to cause behaviour change. The findings placed more emphasis on using social norms in transport programs as tools to facilitate changes in travel behaviours (Riggs 2017). In an earlier study, Schwartz (1977) found that social norm adds little or no predictive power to that already provided by personal norm in a model.

This study applies integrated choice and latent variable (ICLV) modelling to investigate the impact of social norm and personal norms on the explanatory power of transportation mode choice model. Although, social norms was not found to be a significant predictor of behaviour in Schwartz (1977), we expect personal norm and social norm to be significant predictors of observed travel mode choice behaviour in line with Lind et al. (2015) and Bamberg et al. (2007).

\section{Methodology}

\subsection{Case study}

Edinburgh is the administrative capital of Scotland. As of 2018 it had a population of around 518,100 ; this population lives on 263 square kilometres of land with a population density of 1,970 persons per square kilometre (National Records of Scotland, 2018). Edinburgh is Scotland's second-highest populated city and the third city with the highest number of persons living on a square kilometre (Edinburgh City Council, 2016). It is a historic city with many remarkable monuments, which make the city one of UNESCO's World Heritage sites, and also hosts the 
world's largest international art festival in August every year. The city thus attracts lots of visitors and tourist alike each year. The combination of Edinburgh's population dynamics and tourism significantly impacts on the road traffic congestion within the city.

Edinburgh is one of the cities in the United Kingdom with very extensive and efficient public transport systems. Nonetheless, the city is the most congested in Scotland and performs better than only Belfast in the United Kingdom (TomTom International BV, 2016). Car traffic in Edinburgh has been on a rising trajectory since 2009 (TomTom International BV, 2016; Transport Scotland, 2018b) while bus passenger numbers have been declining for the same period (Transport Scotland, 2018b). Moreover, average travel time has been on the rise since 2015 (Transport Scotland, 2015, 2018a) with morning and evening peak travel times $64 \%$ and $73 \%$ longer respectively (Shan \& John, 2015; Edinburgh City Council, 2016;TomTom International BV, 2016; Riley, 2020).

Private cars constitute $36 \%$ of the modal share in Edinburgh; in contrast, buses and tram make up around $27 \%$ of the modal share (Transport Scotland, 2018b, Table 1). Transport Scotland (2017) indicates that almost $71 \%$ of households in Scotland own or have a car available for commuting. The study thus focuses on the wider population of the city of Edinburgh to collect data from households to represent the characteristics of the population; particularly on transport behaviour.

\subsection{Respondents}

The target population of the study was the residents of Edinburgh of aged 17 and above, to ensure that all respondents satisfy the legal driving age requirement. The sampling frame of the survey comprised of 240,147 households stratified into 20 zones based on the 2016 Scottish Index of Multiple Deprivation (SIMD 16) classification and postcodes from the Royal Mail address data. Households were then drawn at random from each zone (stratum) using the inward postcodes (incodes) to generate the sample. The number of households drawn from each stratum was based on its respective weighting in the sampling frame. The sampled households were contacted by mail to complete and return the survey by post to the survey administrator. In total, 551 participants completed and returned the survey questionnaire.

\subsection{Questionnaire design}

Several studies have indicated that Norms has significant impacts on overt behaviour and the intention to use a transport mode (Schwartz, 1977; Cialdini et al., 1991; Bamberg et al., 2007; Belgiawan et al., 2016; Zhang et al., 2016; Hiselius \& Rosqvist, 2016; Riggs, 2017; Long et al., 2015). However, most of these studies investigated the association between norms (perceived social norms and personal norms) and the intention to use a transport mode instead of the actual mode-use (Bamberg et al., 2007; Belgiawan et al., 2015; Hiselius \& Rosqvist, 2016; Riggs, 2017). Based on the studies above, we developed measurement indicators to assess the perceived social norms of the study population and personal norms of the study's participants to empirically investigate their association with individual observed transport mode choices preference in an ICLV model. The primary objective is to investigate whether personal norms and social norms are of comparative significance to objective factors (such as income, age, car ownership, travel time et cetera.) in explaining transport mode choice behaviour using ICLV modelling approach (Schwartz, 1977; Bamberg et al., 2007; Belgiawan et al., 2016; Cialdini et al., 1991; Avineri, 2009a, 2009b). A questionnaire survey was designed to collect data on socio-demographics, 
transport characteristics and information on perceived social norms and personal norms of the study participants. The first section of the questionnaire captured respondents' past and current travel behaviour, the frequency of their trips as well as travel time, cost, car ownership and accessibility of public transport. Next, respondents were asked questions bothering on the general perception and expectation of the reference population (population of Edinburgh). Tenindicator survey instrument was developed to investigate norms (perceived social norms and personal norms). The indicators for this tool include statements on the general perception of cars/PT in society. For example, "Driving is perceived to illustrate a person's power, financial status in society and provide the driver/owner with a positive self-image".

Additionally, to measure individual "personal norms," respondents were asked about their perception about cars/PT usage and their perceived expectation of others to use a car or public transport. For example, "I think people should use public transport more for their work/educational journeys due to the increasing levels of traffic congestion and air pollution in the urban centres", and "I feel morally obligated to use more of public transport due to the impact of our travel behaviour on health and the environment (global warming)". All the statements were measured on a five-point Likert scale ( $1=$ Strongly Disagree; $5=$ Strongly Agree). Some of the indicators were adapted from Bamberg et al. (2007) and Belgiawan et al. (2015).

In the final section of the survey instrument, we asked for information necessary to understand respondents' socio-economic status such as gender, age, marital status, highest education level, annual household income, employment status and household size. The social demographic variables are used in conjunction with other relevant variables, such as perceived social norm and personal norm to estimate the ICLV model.

\section{Sample characteristics}

\subsection{Socio-demographic}

In total, 551 questionnaires were completed and returned. Respondents are aged between 18 and $90(\mu=49.69, \sigma=17.45)$. Fifty-one partially completed responses were deleted from the dataset. This reduced the total valid responses for analysis to 500 cases. All respondents meet the minimum age of 17 at which a person may obtain a driver's licence and drive in the United Kingdom. It was found that $82.8 \%$ of respondents own either full or provisional driving licence, $13.5 \%$ have never held a licence, $3.4 \%$ have surrendered their licence, and none was disqualified from driving. This suggests that at least $96.3 \%$ of respondents are legally eligible to drive in the study area. The next section presents a descriptive analysis of the sample data.

Figure 1 presents the characteristics of the study population; there are fewer males than females in the sample. A total of 349 participants, representing $69.2 \%$, of respondents, reported having at least one car available for use. This statistic is slightly different from similar statistics from Transport Scotland (TS) (Transport Scotland (2018b). However, a chi-square test conducted $\left(x^{2}=\right.$ 1.916 at a p-value of 0.853 at $95 \%$ confidence level) suggested both data sets come from the same population. Similarly, it was found that $35 \%$ of participants commute by driving, while $32 \%$ of them reported taking the bus or tram. The sample data was found not to significantly differ from similar data from TS (Transport Scotland, 2018a). The study further investigated the household income of participants and compared the sample data with similar records from the Scottish Government (Scottish Government, 2018). It observed that the two data sets belong to the same population and do not significantly differ $\left(x^{2}=2.737\right.$ at a $p$-value of 0.603$)$. The sample estimates 
on education show a high proportion (62.7\%) of respondents with at least first degree. Similar statistics could not be sourced for comparison. However, CoEC (2018) indicates that $63.9 \%$ of the working population in Edinburgh have at least a university degree. Again this estimate does not deviate much from the $62.7 \%$ of the sample data. Thus the sample data is assumed to characterise as the study population.

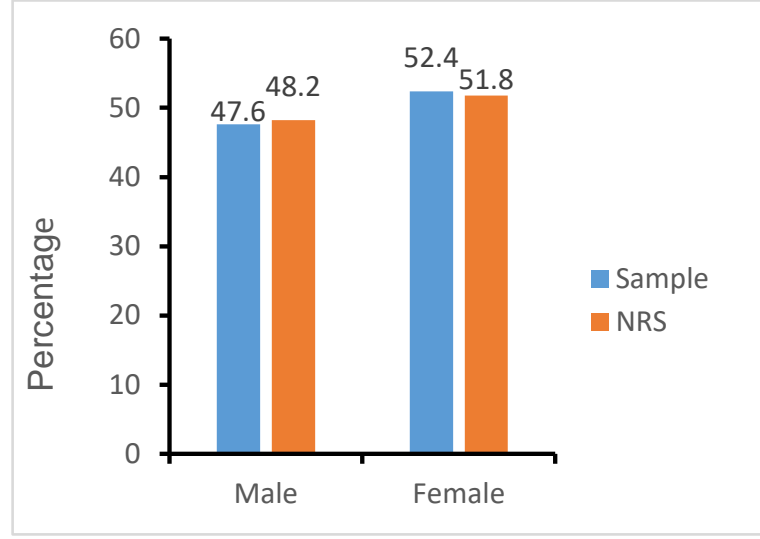

a). Gender

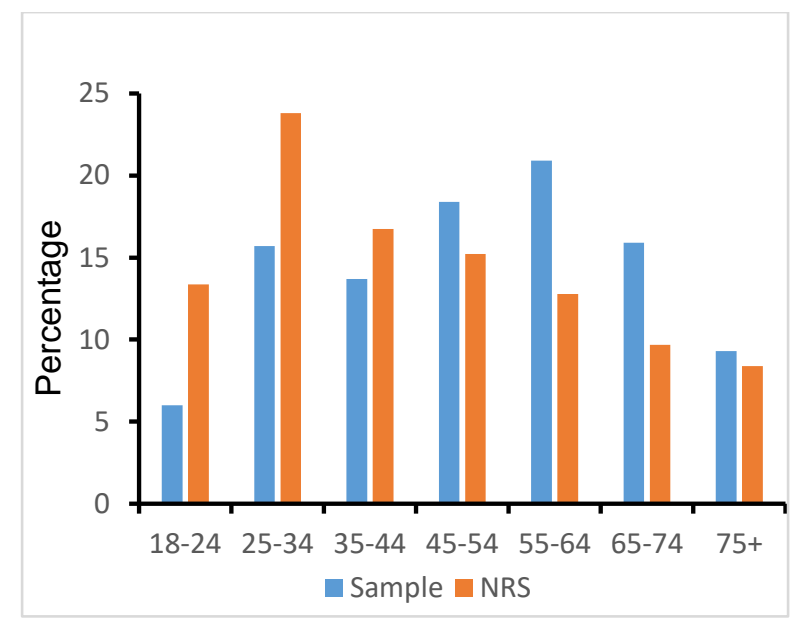

c). Age

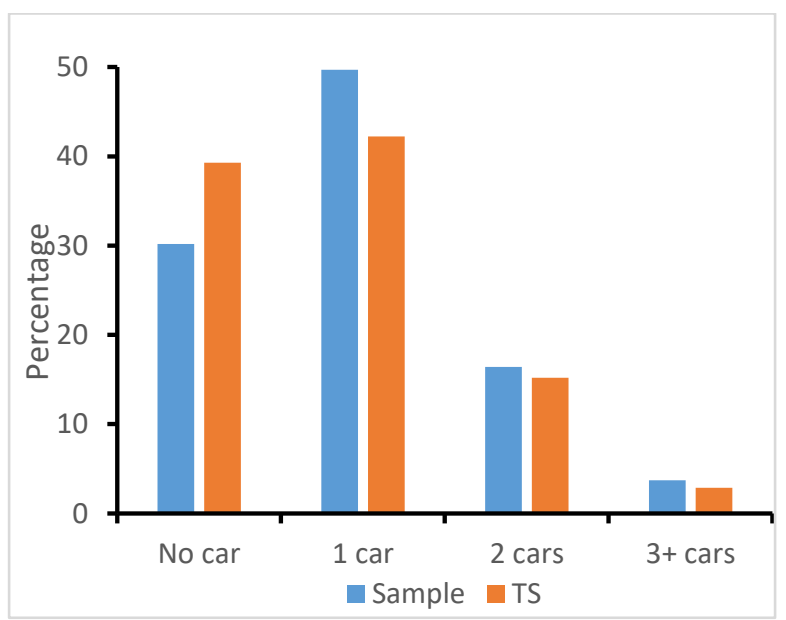

e). Car Availability

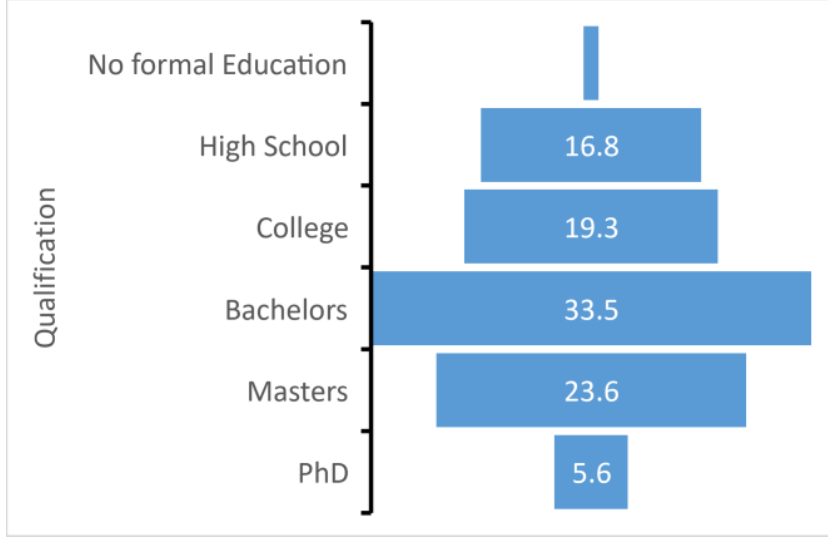

b). Qualification

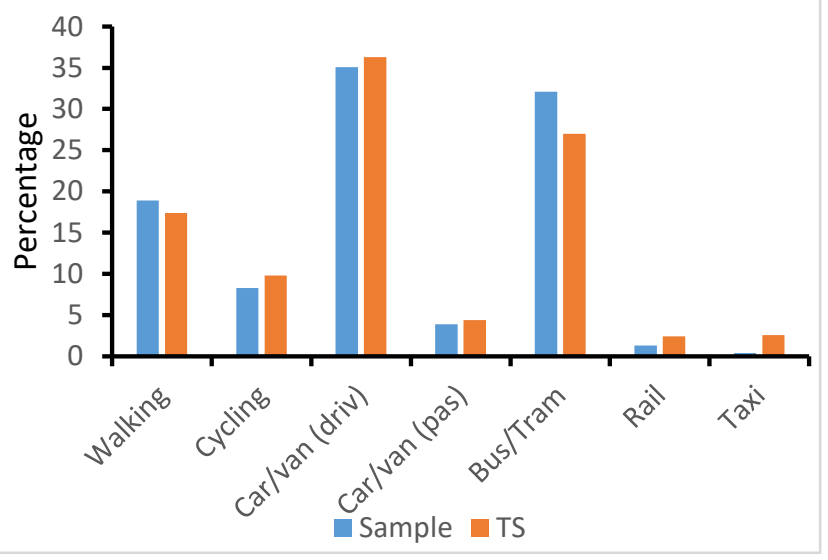

d). Modal Share

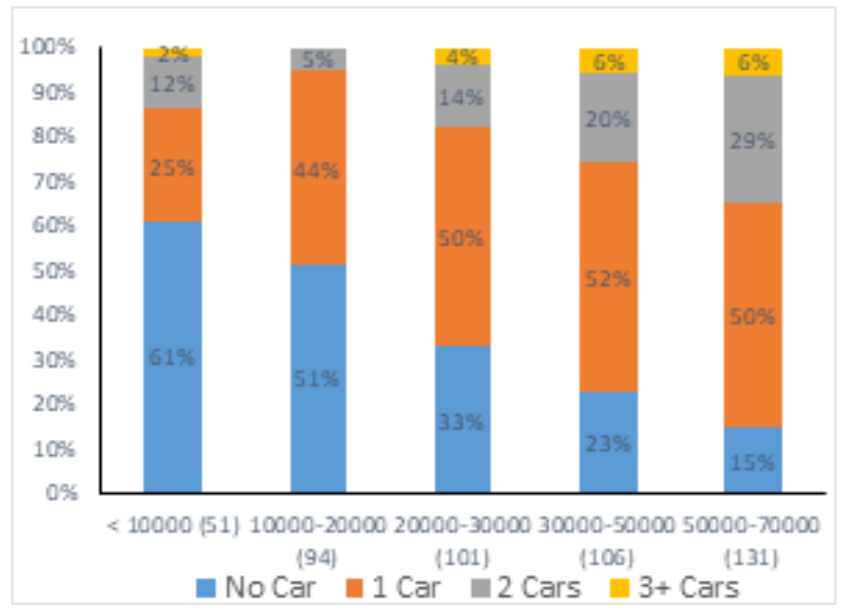

f). Car availability by Income

Figure 1: Sample Characteristics 
Figure 1(f) shows a plot of car ownership against household income. The figure demonstrates the effect of income on the number of cars owned by a household. It is seen that not only does the proportion of car owners increase with increasing household income, the number of cars owned increases as well.

\subsection{Attitudinal variables}

We investigate whether there is a significant difference in norm between PT users, (private) car users and active travellers (Non-Motorised Transport (NMT)) in the sample data. As indicated previously, the behavioural data set was measured on a 5-point ordinal scale. For this reason, we employed Kruskal-Wallis Test and Mann Whitney U-test for this assessment. Table 1 presents the results of the Kruskal-Wallis Test. First, the modal share data was recoded into three categories based on their transport choices for commuting (NMT for active travel such as walking and cycling; Car for car users and PT for Public transport users). As indicated in Table 1: the means of six out of the ten measurement indicators used significantly differ between the three groups at $99 \%$ confidence level; one variable differs at $90 \%$ confidence level, and the remaining three statements were found statistically non-significant.

Table 1: Comparison of NMT, Car and PT users

\begin{tabular}{|c|c|c|c|c|c|c|c|c|}
\hline \multirow{3}{*}{$\begin{array}{l}\text { Indicator Variable } \\
\mathrm{Nr} 1 \text { : Driving is perceived to illustrate a person's power ... }\end{array}$} & \multicolumn{2}{|c|}{ Car (192) } & \multicolumn{2}{|c|}{ PT (170) } & \multicolumn{2}{|c|}{ NMT (130) } & \multirow{2}{*}{\multicolumn{2}{|c|}{$\begin{array}{l}\text { Chi- } \\
\text { square }\end{array}$}} \\
\hline & Mean & SD & Mean & SD & Mean & SD & & \\
\hline & 2.18 & 1.12 & 2.51 & 1.16 & 2.75 & 1.18 & 20.48 & *** \\
\hline $\mathrm{Nr} 2: \mathrm{PT}$ is seen as a second-best option in society & 2.66 & 1.17 & 2.80 & 1.22 & 2.89 & 1.19 & 3.10 & \\
\hline Nr3 : PT is perceived to provide environmentally cleaner transport & 3.80 & 0.90 & 4.02 & 0.80 & 4.05 & 0.76 & 8.30 & *** \\
\hline Nr4 : PT is beneficial to the environment and our health. & 3.90 & 0.86 & 4.06 & 0.74 & 4.08 & 0.72 & 4.79 & * \\
\hline $\mathrm{Nr} 5$ :Family/friends believe PT is beneficial to the environment and our health & 3.59 & 0.89 & 3.57 & 0.86 & 3.74 & 0.89 & 3.91 & \\
\hline Nr6 : Most of my family and friends use public transport & 2.60 & 0.99 & 3.21 & 1.14 & 3.00 & 1.14 & 28.06 & *** \\
\hline $\mathrm{Nr} 7$ : If my family and friends change their travel choices, I may do the same & 1.97 & 0.88 & 1.99 & 0.87 & 1.95 & 0.90 & 0.30 & \\
\hline Nr8 : I think people should use PT more ... & 3.66 & 0.96 & 4.07 & 1.00 & 4.06 & 0.98 & 28.23 & *** \\
\hline $\mathrm{Nr9}:$... family/friends will agree if I use PT instead of a car ... & 3.13 & 0.96 & 3.82 & 0.92 & 3.86 & 0.84 & 62.45 & *** \\
\hline Nr10 : I feel morally obligated to use more of PT for the environment... & 2.84 & 1.10 & 3.26 & 1.24 & 3.35 & 1.20 & 18.55 & $\star \star \star *$ \\
\hline
\end{tabular}

Additionally, we performed Mann-Whitney $U$ test to investigate the relationship between households with at least a car and those without (refer to Table 2 for details). The test found some significant difference between car owners and non-car owners in eight of the ten indicators. The analysis indicates that the mean score of non-car owners and non-car mode users are significantly higher than car owners and car users. Non-car owners and non-car mode users tend to rate the social value of cars more highly than car owners. For example, non-car owners agree more with statements such as: "The car is perceived to illustrate a person's power, financial status and provide the driver/owner with a positive self-image", and "PT is seen as the second-best option in society". 
Table 2: Comparison of car and Non-car owners

\begin{tabular}{|c|c|c|c|c|c|c|c|}
\hline \multirow{2}{*}{ Indicator Variable } & \multicolumn{2}{|c|}{$\begin{array}{c}\text { Car Owners } \\
(341)\end{array}$} & \multicolumn{2}{|c|}{$\begin{array}{c}\text { Non-car Owners } \\
(156)\end{array}$} & \multirow[t]{2}{*}{$\mathbf{U}$} & \multirow{2}{*}{\multicolumn{2}{|c|}{$\begin{array}{c}\text { z- } \\
\text { statistics }\end{array}$}} \\
\hline & Mean & SD & Mean & SD & & & \\
\hline $\mathrm{Nr} 1$ : Driving is perceived to illustrate a person's power ... & 2.30 & 1.12 & 2.76 & 1.22 & 20640 & -3.903 & $* \star *$ \\
\hline $\mathrm{Nr} 2: \mathrm{PT}$ is seen as a second-best option in society & 2.68 & 1.18 & 2.97 & 1.21 & 23283 & -2.496 & ** \\
\hline $\mathrm{Nr} 3: \mathrm{PT}$ is perceived to provide environmentally cleaner transport & 3.89 & 0.87 & 4.04 & 0.83 & 24056 & -2.097 & ** \\
\hline Nr4: PT is beneficial to the environment and our health. & 3.94 & 0.84 & 4.10 & 0.74 & 24270 & -1.956 & ** \\
\hline Nr5 : Family/friends believe PT is beneficial to the environment and our health & 3.64 & 0.88 & 3.59 & 0.88 & 25821 & -0.742 & \\
\hline Nr6 : Most of my family and friends use public transport & 2.80 & 1.06 & 3.17 & 1.17 & 21671 & -3.368 & *** \\
\hline $\mathrm{Nr} 7$ : If my family and friends change their travel choices, I may do same & 1.98 & 0.88 & 1.97 & 0.88 & 26214 & -0.043 & \\
\hline Nr8 : I think people should use PT more ... & 3.82 & 0.98 & 4.12 & 1.00 & 21343 & -3.836 & *** \\
\hline $\mathrm{Nr} 9: \ldots$ family/friends would agree if I use PT instead of car ... & 3.42 & 0.96 & 3.86 & 0.96 & 19336 & -4.681 & *** \\
\hline Nr10: I feel morally obligated to use more of PT for the environment... & 2.99 & 1.15 & 3.44 & 1.23 & 20755 & -4.008 & *** \\
\hline
\end{tabular}

The results of indicators 1 and 2 in Tables 1 and 2 indicates that respondents without cars and non-car users rate car ownership favourably than car owners. It can be argued from the results that non-car owners may be overestimating the impact of car ownership on self-image or perhaps making an excuse to own one in future. It is also found that car owners agree less with the statement " $P T$ is generally perceived to provide an environmentally cleaner choice of transport than a car," and "PT is beneficial to the environment and our health."

As expected, non-car owners and non-car users agree more with statements favouring PT and active travelling than car owners. It stands to reason that on average, car owners slightly differ in attitude and perception from non-car owners and non-car users. Car owners and users seem less sensitive to the externalities of driving and significantly differ in perception and personal values from non-car owners and non-car mode (NMT and PT) users. In general, the results in Tables 1 and 2 are consistent with the findings in similar studies and seems to suggest that respondents scoring high on the indicators meant for assessing personal norms favour active and PT travel mode (Belgiawan et al., 2016; Erikssona et al., 2006; Zhang et al., 2016). The high mean scores of indicators 1 and 2 for NMT users, PT users and non-car owners compared to car users and car owners could be resulting from cognitive dissonance and possibly explains why non-car owners project cars and driving negatively. However, what is unclear is whether the perception of non-car owners/users towards PT and active modes is because of the external impact of driving on the environment and health or affordability (Belgiawan et al., 2016).

\section{Model Estimation}

\subsection{Construction of latent variables}

Two main methods were used for defining the latent constructs of this study. First, we performed an exploratory factor analysis (EFA) using Maximum likelihood (ML) factor analysis with Promax rotation. The latent constructs are extracted from the 10-item indicators designed for the measurement of norms using SPSS software package. The second phase involved confirmatory factor analysis (CFA) in Amos Software package to validate the factors extracted during the EFA. The CFA was performed to confirm the validity, reliability and collinearity of the latent factors.

\section{Exploratory factor Analysis}


We performed maximum likelihood (ML) factor analysis with the indicator statements; ML estimator was adopted because of its robustness in handling ordinal and non-normally distributed data (Dannewald et al., 2008; Muthén \& Muthén, 2010). The factor extraction produced three factors (personal norms, social norms and symbolism) from 10-item indicators. The factors were constructed based on all ten statements used for measuring norm and $80 \%$ of the sample data. Two statements; "Most of my family and friends use public transport for their work/educational journeys" and "If my family and friends change their travel choices, then, maybe I would do same" had very low factor loading ( 0.165 and 0.079 respectively) and were consequently omitted from the analysis. Constructs with eigenvalues greater than one were retained. Overall, three factors explaining $61.58 \%$ of the variance in responses were retained. The first factor is named social norm (SocNorm) consistent with (Belgiawan et al., 2016). This factor accounts for $33.55 \%$ of the variance and describes the reference groups' perception of cars, public transport and the environment. Factor two is named Personal norm (PerNorm) and accounts for $15.82 \%$ of the variance. This factor defines the respondents' perception of cars, public transport and their impact on the environment. The third factor also accounts for $12.21 \%$ of the variance and describes the symbolism of driving. This factor is, therefore, named symbolism. Table 3 presents the results of the factor analysis and Cronbach's Alpha test of construct reliability performed on the three factors. Cronbach's Alpha test indicates that all three factors met the requirement for reliability ( $\alpha$ $\geq 0.70$ ) (Cronbach, 1951; Kline, 2011).

Table 3: Exploratory Factor Analysis of the attitudinal variables.

\begin{tabular}{|c|c|c|c|c|c|c|}
\hline \multirow{2}{*}{\multicolumn{2}{|c|}{ Indicator variables }} & \multirow{3}{*}{ Mean } & \multirow{3}{*}{ SD } & \multicolumn{3}{|c|}{ Factor } \\
\hline & & & & \multirow{2}{*}{$\begin{array}{c}\begin{array}{c}\text { SocNorm } \\
(33.57 \%)^{\mathrm{a}}\end{array} \\
0.779\end{array}$} & \multirow{2}{*}{$\begin{array}{c}\text { PerNorm } \\
(15.82 \%)\end{array}$} & \multirow{2}{*}{$\begin{array}{c}\text { Symbolism } \\
\mathbf{( 1 2 . 2 1 \% )}\end{array}$} \\
\hline Variable $^{b}$ & Cronbach's Alpha & & & & & \\
\hline $\mathrm{Nr}^{\mathrm{b}}$ & $\begin{array}{l}\text { PT is perceived to provide environmentally cleaner } \\
\text { transport }\end{array}$ & 3.94 & 0.856 & 0.987 & & \\
\hline Nr4 & PT is beneficial to the environment and our health. & 4.10 & 0.808 & 0.778 & & \\
\hline Nr5 & $\begin{array}{l}\text { Family/friends believe PT is beneficial to the } \\
\text { environment and our health }\end{array}$ & 3.63 & 0.885 & 0.465 & & \\
\hline Nr8 & I think people should use PT more ... & 3.92 & 0.992 & & 0.663 & \\
\hline Nr9 & .. family/friends would agree if I use PT instead of car... & 3.55 & 0.976 & & 0.660 & \\
\hline Nr10 & $\begin{array}{l}\text { I feel morally obligated to use more of PT for the } \\
\text { environment... }\end{array}$ & 3.12 & 1.195 & & 0.604 & \\
\hline Nr1 & Driving is perceived to illustrate a person's power ... & 2.45 & 1.178 & & & 0.856 \\
\hline Nr2 & PT is seen as a second-best option in society & 2.77 & 1.202 & & & 0.664 \\
\hline
\end{tabular}

\section{Confirmatory Factor Analysis}

We performed confirmatory factor analysis to validate the factors extracted during the maximum likelihood factor analysis, using AMOS Structural Equation Modelling (SEM) package. The results of the confirmatory factor analysis are presented in Table 4. The results of the validity and reliability test conducted on the measurement model indicated that the model achieved all requirements for convergent validity (AVE $>0.50)$, and divergent validity and reliability $(C R>0.69)$. The goodness-of-fit statistics for the CFA model similarly suggests that the final model satisfied all thresholds recommended for assessing goodness-of-fit (see Kline, 2011), indicating that the measurement model satisfactorily fits the sample data. 
Table 4: Measure of model fitness.

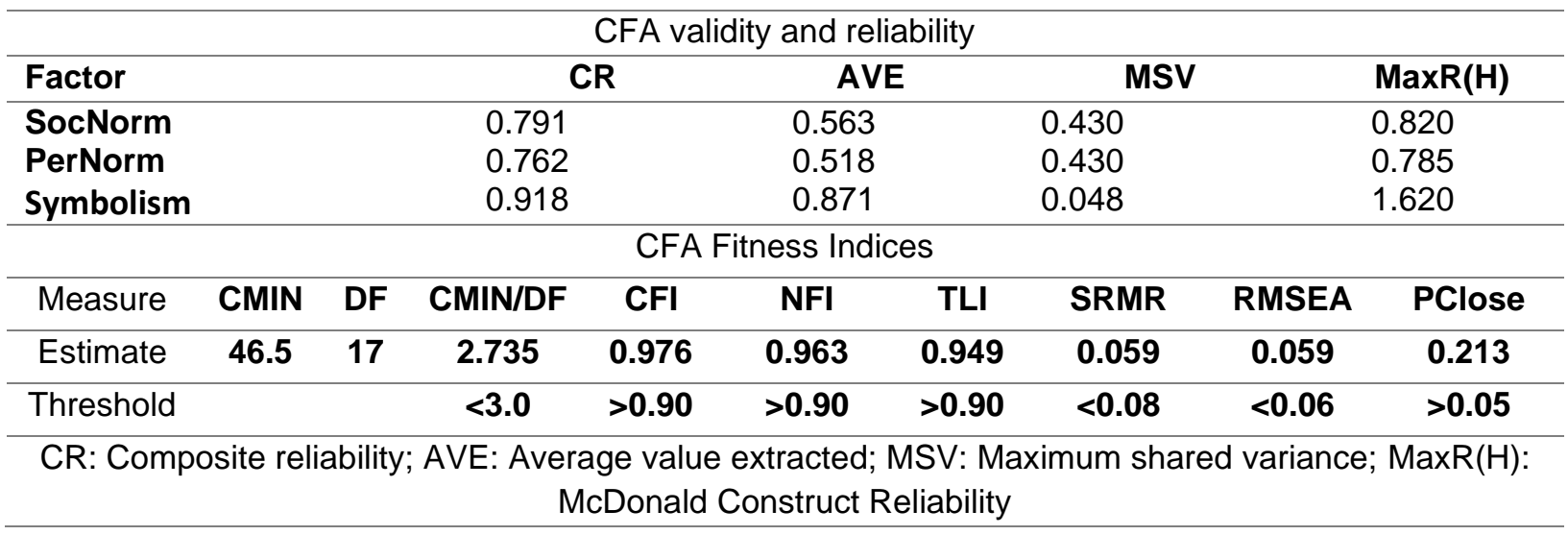

It was observed that the standardised regression weight and squared multiple correlation of one of the indicators (Nr1) of Symbolism exceeded unity (1.659 and 2.753 respectively) (Hair et al., 1998, pg.610). Opinions are split on the meaning and implication of standardised coefficients greater than unity (Hair et al., 1998, Jöreskog, 1999). Hair et al. (1998, pg.610) suggest this is an indication of poor identification and recommends the elimination of such constructs. Therefore, following the advice of Hair et al. (1998, pg.610), the latent construct "Symbolism" is dropped.

Linear regression models were estimated with the confirmed latent variables as dependent variables and the socio-demographic variables (such as Age, Income, Gender and Education) as explanatory variables to develop the latent factor structural equations. This was done to characterise and understand the mobility behaviours of different segments of the population based on the latent factors. Table 5 shows the results of the regression analysis. High_Educ is a dummy variable; 1 for respondents with a university degree, otherwise it is 0 . No_of_Cars represents the number of cars available in the household. Age_PerNorm is a dummy variable; 0 for respondents aged "25 to 64 " and 1 for respondents aged "18 to 24 " or above 64 years.

Table 5: Regression with CFA factors dependent variables.

\begin{tabular}{|c|c|c|c|c|}
\hline Factor & \multicolumn{2}{|c|}{ PerNorm } & \multicolumn{2}{|c|}{ SocNorm } \\
\hline Variable & $\beta$ & S.E & $\beta$ & S.E. \\
\hline No_of_Cars & $0.295^{\star \star \star}$ & 0.080 & $0.169^{\star \star \star}$ & 0.059 \\
\hline High_Education & $0.233^{\star \star \star}$ & 0.108 & $0.206^{\star \star \star}$ & 0.056 \\
\hline Age_PerNorm & $0.247^{\star \star \star}$ & 0.077 & & \\
\hline $\mathbf{R}^{2}$ & 0.077 & & 0.054 & \\
\hline Adjusted $\mathrm{R}^{2}$ & 0.067 & & 0.047 & \\
\hline
\end{tabular}

Two latent constructs were retained from the CFA analysis of the ten indicators, namely; "personal norm" (PerNorm) and "social norms" (SocNorms) and used in the regression analysis. The results of the regression analysis suggest that membership of Personal Norms latent construct are likely to be either aged between 18 and 24 or above 64 years. The estimates in Table 5 indicate that members of this class are likely to have a university degree (at least have a first degree). They are also found to have a car available for household use. On the other hand, individuals belonging to the Social Norms latent construct have similar characteristics as the 
membership of the Personal Norms latent construct. However, unlike Personal Norms, membership of this class is less influenced by age.

\subsection{Integrated Choice and latent variable model}

Integrated and latent variable model (ICLV) consists of two components: a discrete choice model and a latent variable model. The factors extracted from the CFA and used for the regression analysis above are used as latent variables in addition to observed socio-demographic variables underlying the latent attitude (such as age and education). The model estimation is done in the Biogeme software (Bierlaire, 2018). We estimate an integrated choice and latent variable model. The estimated model contains choices between Cars, PT and Active mode of transport (NMT) (such as walking and cycling). The framework of the integrated choice model is illustrated in Figure 2. We used the indicators of the latent attitudes "PerNorm" and "SocNorm" as shown in Figure 2 for the specification of the measurement model. The Measurement model mapping the observed indicators $I_{n}$ into the latent variables for the latent variable sub-model is shown in equation (1) (Ben-Akiva et al., 1999; Ben-Akiva \& Boccara, 1995; Bierlaire, 2018a).

$$
I_{n}=\alpha_{n}+\lambda_{n} X_{n}^{*}+\varepsilon_{n}, \quad \forall n, \varepsilon_{n} \sim N\left(0, \sum_{\varepsilon_{n}}\right)
$$

Where:

$I_{n}$ is a vector of indicators of the latent variables

$\mathrm{X}_{\mathrm{n}}^{*}$ is a vector of socio-demographics underlying the latent attitude (PerNorm and SocNorm),

$\alpha_{n}$ and $\lambda_{n}$ : are vectors of unknown parameters to be estimated and

$\varepsilon_{n}$ normally distributed error term with mean 0 .

Equation (2) below shows the structural model of the latent variable model; the model describes the latent variables using the observed socio-demographic variables. This framework makes the integration of the latent variables sub-models and the discrete choice sub-models.

Where:

$$
X_{n}^{*}=K X_{n}+v_{n}, v_{n} \sim N(0, \psi)
$$

$\mathrm{X}_{\mathrm{n}}^{*}$ is a vector of the latent variables $\mathrm{L}$ is the number of latent variables,

$X_{n}$ is a vector of the observed socio-demographics describing the latent variables

$\mathrm{K}$ is a matrix of unknown coefficients mapping the observed socio-demographics variables $X_{n}$ to the latent variables. 


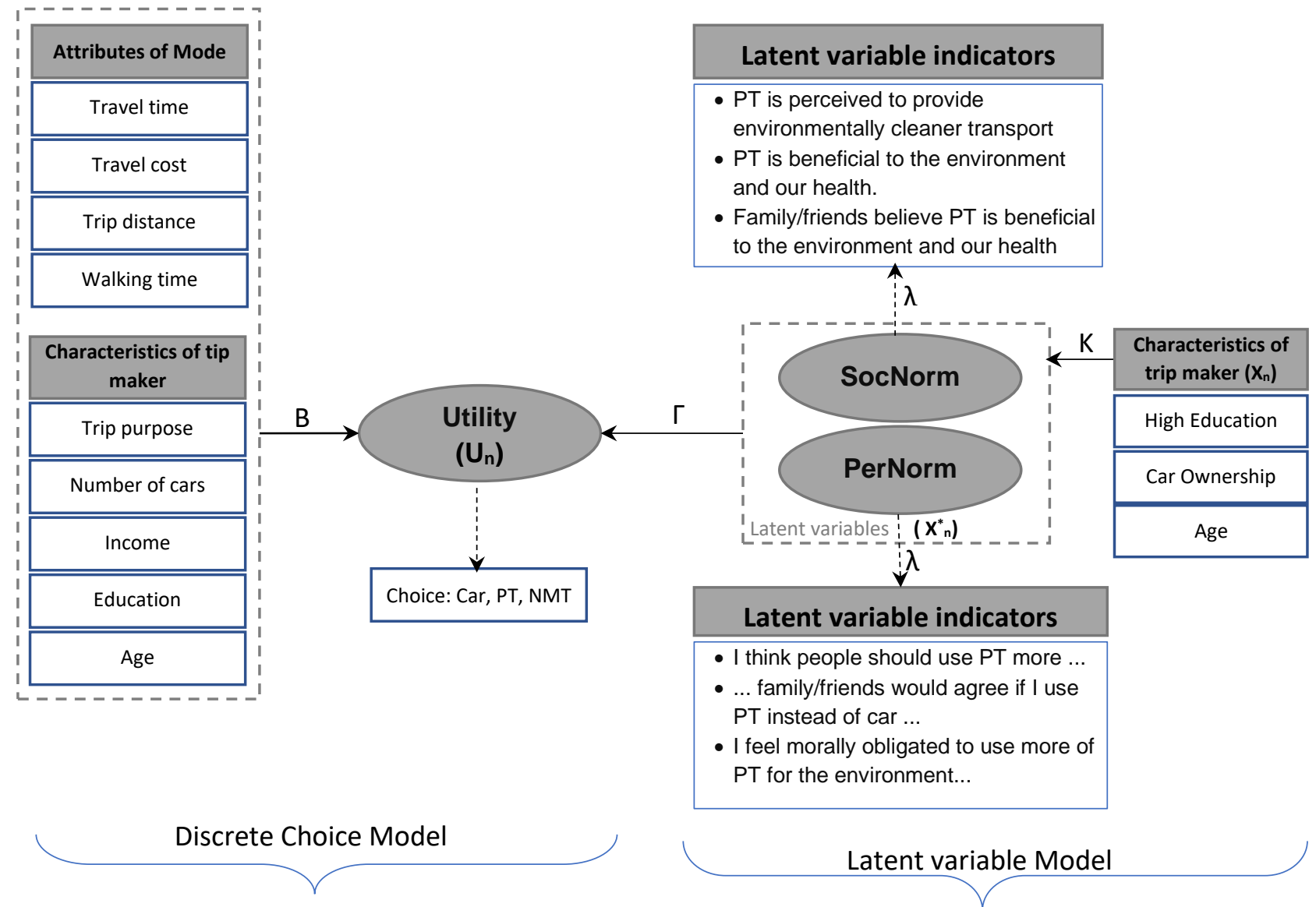

Figure 2: Framework of the ICLV model

The latent variable "PerNorm" as discussed in the previous section, was included in the integrated choice model. The measurement equation below was used for the measurement or structural aspect of the model: three indicators were used to measure the latent variable "PerNorm" as shown in Figure 1. Using equation (1), the measurement model of the latent variable sub-model is expressed below. Equations (3) to (5) are the measurement equations for the latent variable "PerNorm". Equation (5) was normalised by setting the intercept to 0 and the coefficient of the latent attitude to 1. (Ben-Akiva \& Boccara, 1995)

$$
\begin{aligned}
& \operatorname{Nr} 8=\alpha_{8}+\lambda_{8} * \text { PerNorm }+\varepsilon_{8} \\
& \operatorname{Nr} 9=\alpha_{9}+\lambda_{9} * \text { PerNorm }+\varepsilon_{9} \\
& \text { Nr10 }=\alpha_{10}+\lambda_{10} * \text { PerNorm }+\varepsilon_{10} ; \alpha_{10}=0, \quad \lambda_{10}=1 \\
& \text { Where PerNorm is a vector of (Education, Car Availability(dummy), Age) }
\end{aligned}
$$

Similarly, as can be seen in Figure 1, three indicators were used to measure the latent attitude "SocNorm". Equations (6) to (8) are the measurement equations for the latent attitude. Again, equation (6) was normalised by setting the intercept to 0 and the coefficient of the latent attitude to 1.

$$
\begin{aligned}
& \mathrm{Nr} 3=\alpha_{3}+\lambda_{3} * \text { SocNorm }+\varepsilon_{3} ; \alpha_{3}=0, \quad \lambda_{3}=1 \\
& \mathrm{Nr} 4=\alpha_{4}+\lambda_{4} * \text { SocNorm }+\varepsilon_{4} \\
& \mathrm{Nr} 5=\alpha_{5}+\lambda_{5} * \text { SocNorm }+\varepsilon_{5}
\end{aligned}
$$

Where SocNorm is a vector of (Education, Car Availability (dummy))

Using the framework in Figure 2, equation (2) can be written as follows: 


$$
\begin{aligned}
& X_{\text {PerNorm }}^{*}=K X_{\text {PerNorm }}+v_{\text {PerNorm }} \\
& X_{\text {SocNorm }}^{*}=K X_{\text {SocNorm }}+v_{\text {SocNorm }}
\end{aligned}
$$

The error terms $\varepsilon_{n}$ and $v_{n}$ are assumed to independent. $A, \lambda$ and $K$ are unknown parameters to be estimated.

We further estimated a multiple-choice model with similar specifications as the integrated choice model, however, without the latent variables. This model is used as a reference model (base model) to evaluate the integrated choice model. The base and ICLV models were assumed to be between the recoded modal share discussed under section 4.2. These are private motorised mode (Car) which consist of taxi, car as driver and passenger; Public transport (PT) which includes bus, tram, and train and Active modes (NMT), which comprises of walking and cycling. The likelihood of a respondent selecting a given alternative with the ICLV model is given by the joint probability of observing the alternative and the indicators of the latent attitudes (PerNorm and/or SocNorm). PT mode was used as the reference alternative (the intercept term was normalised to 0 ) in the utility equations both for the base model and ICLV model.

The discrete choice component of the ICLV model consists of structural and measurement sub-models which are based on the assumption that when individuals are presented with a finite set of mutually exclusive alternatives $n$, they will choose the alternative that maximises their utility (Ben-Akiva \& Lerman, 1985). The structural component (utility function) of the discrete choice sub-model consists of the systematic component $\mathrm{V}($.$) and the random error component \varepsilon_{n}$.

$$
U_{n}=V\left(X_{n}, X_{n}^{*} ; \mathrm{B}, \Gamma\right)+\eta_{n} \text { or } A+B X_{n}+\Gamma X_{n}^{*}+\eta_{n}, \quad \varepsilon_{n} \sim N\left(0, \sum_{\eta}\right)
$$

Where:

$U_{n}$ is the random utility of alternative $n, x n$ is a vector or observed variables

$\mathrm{X}_{\mathrm{n}}^{*}$ is a vector of the latent variables

$A$ is an intercept for alternative $n$,

$B$ and $\Gamma$ are the matrices of estimates mapping the observed and latent variables to the alternatives $\mathrm{n}$

$\varepsilon_{\mathrm{n}}$ is a vector of random error terms associated with the utility terms and

$\Sigma_{\eta}$ is the covariance of the random error terms.

The choice model component of discrete choice sub-model of the ICLV model is based on utility maximisation and given by equation (12)

Where:

$$
y_{i}=\left\{\begin{array}{cc}
1, & \text { if } \quad U_{i} \geq U_{j,} \quad \forall j \neq i \\
0, & \text { otherwise }
\end{array} \quad i=\text { Car, } P T, N M T\right.
$$

$y_{i}$ is the choice indicator; this is 1 if the alternative is chosen, 0 otherwise.

The ICLV model comprises of equations 1, 2, 11 and 12, equations 1 and 2 are the latent variable sub-models and equations 11 and 12 are the discrete choice sub-model. Using equations 11 and 12 and the assumption that all the random error terms are independent of each other, we can integrate over the joint distribution of the latent variables; this produces a multidimensional 
integral; the number of latent variables defines the dimension of the joint likelihood function of the model (Ben-akiva et al., 2002; Kamargianni \& Amalia, 2014; Temme et al., 2008)

Since individuals make choices which are independent of each other, we can assume that the error terms of equations 1, 2, 11 and 12 are independent of each other. Therefore, the likelihood function of observing a given choice indicator $y_{n}$, is given by the joint probability of observing the choice indicators and the indicators of the latent variables. This can be expressed mathematically as:

$$
f\left(y, I \mid X, X^{*} ; \alpha, \lambda, K, B, \Gamma ; \Sigma_{\varepsilon} \Sigma_{v} \Sigma_{\eta}\right)=\int_{X^{*}} P\left(y \mid X, X^{*} ; B, \Gamma, \Sigma_{\eta}\right) f_{3}\left(I \mid X, X^{*} ; \alpha, \lambda, \Sigma_{\varepsilon}\right) f_{1}\left(X \mid K, \Sigma_{v}\right) d X^{*}
$$

The first term of the integrand relates to equation 11, while the second and third terms relate to equations 1 and 2, respectively. Assuming a linear function and a normally distributed error term for the choice model. The choice model component of the likelihood function takes the form of a standard choice model, with the utility being a function of the latent constructs. The probability function is derived from equations 11 and 12 based on the assumption of i.i.d. error term, standard Gumbel. (Ben-Akiva et al., 2002):

\subsection{Results and Discussions}

\subsection{Results and interpretations}

Four different models were tested, the base model without latent variable and three integrated choice and latent variable (ICLV) models with personal norm and social norm as latent variables to investigate their significance or otherwise. Estimation results of the base model and the ICLV models are presented in Table 6 . Model 1 is the base model constructed without any of the two latent variables and models 2, 3 and 4 incorporate Personal Norms, Social Norms and, personal norms and social norms as latent variables, respectively.

We observe from the estimates in Table 6 that all the utility parameters of the modal attributes, individual characteristics and the latent variables (i.e. travel time, distance, age, education, income and cost) have expected signs and similar estimated values for both models. The results are congruent with the results of related literature (Ben-akiva, 1999; Dannewald et al., 2008; Ortuzar et al., 2011; Temme et al., 2008a; Yáñez et al., 2010). It is also observed that in the absence or presence of personal norm in models 3 and 4, social norm was found insignificant in the ICLV models. Thus model 2 involving only personal norm is adopted for the estimation of indicators (such as choice probabilities, market shares and elasticities) for comparison with the base model. ICLV model in Tables 7 to 11 refers to model 2.

The travel time for private motorised mode and PT are observed to reduce the likelihood and probability of choosing PT and Car modes. The cross and direct demand elasticities are shown in Table 11 and confirm the results in Table 6. They indicate that an increase in the travel time of either PT or Car mode will result in the reduction of demand for either alternative. The values of the cross elasticity of demand of the alternatives confirm that private motorised mode and PT modes are substitute goods; thus, increasing the travel time and cost of either alternative will result in increased demand for the other alternative.

Consistent with extant literature (Limtanakool et al., 2006; Lind et al., 2015), the results reveal that active travelling is negatively impacted by trip length. The results indicate that respondents 
are likely to walk for shorter distances. However, as the trip length increases, respondents will either drive or use PT.

Table 6: Model estimation results

\begin{tabular}{|c|c|c|c|c|c|c|c|c|}
\hline & \multirow{2}{*}{\multicolumn{2}{|c|}{$\begin{array}{l}\text { Base Model } \\
\text { (Model 1) }\end{array}$}} & \multicolumn{6}{|c|}{ ICLV Model } \\
\hline & & & \multicolumn{2}{|c|}{$\begin{array}{c}\text { Personal Norm } \\
\text { (Model 2) }\end{array}$} & \multicolumn{2}{|c|}{$\begin{array}{l}\text { Social Norm } \\
\text { (Model 3) }\end{array}$} & \multicolumn{2}{|c|}{$\begin{array}{c}\text { Personal \& Social } \\
\text { Norm (Model 4) }\end{array}$} \\
\hline \multicolumn{9}{|c|}{ Discrete Choice Model } \\
\hline Variable & Estimate & t-test & Estimate & t-test & Estimate & t-test & Estimate & t-test \\
\hline$A S C_{C a r}$ & -3.08 & -3.04 & -3.16 & \begin{tabular}{|l|}
-2.98 \\
\end{tabular} & -2.95 & -2.87 & -3.36 & -3.02 \\
\hline$A S C_{N M T}$ & -3.79 & -4.37 & -3.80 & -4.40 & -3.75 & -4.31 & -3.85 & -4.36 \\
\hline$\beta_{\text {Age_NMT }}$ & -0.22 & -2.35 & -0.24 & -2.57 & -0.22 & -2.34 & -0.24 & -2.56 \\
\hline$\beta_{\text {Age_PT }}$ & -0.51 & -1.89 & -0.59 & -2.16 & -0.51 & -1.91 & -0.59 & -2.11 \\
\hline$\beta$ Cost_Car & -0.10 & -0.99 & -0.08 & -0.85 & -0.09 & -0.92 & -0.09 & -0.93 \\
\hline$\beta_{\text {Cost_PT }}$ & -0.29 & -2.33 & -0.31 & -2.39 & -0.30 & -2.38 & -0.31 & -2.39 \\
\hline$\beta_{\text {Dist_NMT }}$ & -0.17 & -3.63 & -0.18 & -3.42 & -0.17 & -3.66 & -0.18 & -3.39 \\
\hline$\beta$ Educ_NMT & 0.48 & 3.80 & 0.44 & 3.45 & 0.47 & 3.74 & 0.45 & 3.51 \\
\hline$\beta_{\text {Gender_Car }}$ & 0.49 & 1.83 & 0.54 & 1.92 & 0.49 & 1.81 & 0.53 & 1.88 \\
\hline$\beta$ Income_PT & -0.19 & -1.90 & -0.21 & -2.06 & -0.19 & -1.96 & -0.20 & -1.98 \\
\hline$\beta_{\text {No.Of.Cars }}$ & 1.81 & 8.81 & 1.77 & 7.92 & 1.79 & 8.63 & 1.78 & 7.87 \\
\hline$\beta_{\text {TraTime_Car }}$ & -0.39 & -2.35 & -0.38 & -2.12 & -0.37 & -2.23 & -0.41 & -2.23 \\
\hline$\beta$ TraTime_PT & -0.20 & -1.99 & -0.22 & -2.02 & -0.20 & -2.05 & -0.2 .1 & -1.90 \\
\hline$\beta_{\text {Trip_Freq }}$ & -0.23 & -2.19 & -0.27 & -2.45 & -0.23 & -2.17 & -0.27 & -2.45 \\
\hline$\beta$ PTAccessTime & 0.22 & 2.60 & 0.22 & 2.70 & 0.22 & 2.59 & 0.22 & 2.68 \\
\hline$\beta$ Work_Trip & -0.87 & -2.17 & -0.86 & -2.24 & -0.78 & -2.12 & -0.93 & -2.37 \\
\hline$\beta$ PerNorm_PT & - & - & 0.05 & 0.30 & - & - & 0.03 & 0.21 \\
\hline$\beta$ PerNorm_Car & - & - & -0.72 & -2.90 & - & - & -0.57 & -2.59 \\
\hline$\beta$ SocNorm_PT & - & - & - & - & 0.03 & 0.34 & -0.04 & -0.20 \\
\hline$\beta$ SocNorm_Car & - & - & - & - & -0.08 & -0.72 & 0.20 & 0.86 \\
\hline \multicolumn{9}{|c|}{ Latent Variable Model } \\
\hline Variable & & & Estimate & t-test & Estimate & t-test & Estimate & t-test \\
\hline ASC $_{\text {PerNorm }}$ & & & 0.20 & 1.41 & & & 0.21 & 0.71 \\
\hline$\beta_{\text {Age_PerNorm }}$ & & & 0.35 & 2.98 & & & 0.63 & 3.32 \\
\hline$\beta_{\text {CarAvai_PerNorm }}$ & & & -0.58 & -4.00 & & & -0.74 & -3.61 \\
\hline$\beta_{\text {Educ_PerNom }}$ & & & 0.47 & 3.82 & & & 0.79 & 4.02 \\
\hline$\alpha_{8}$ & & & 0.93 & 11.50 & & & 1.20 & 9.69 \\
\hline$\alpha_{9}$ & & & 0.43 & 6.71 & & & 0.57 & 6.71 \\
\hline$\lambda_{8}$ & & & 1.12 & 10.7 & & & 1.02 & 8.28 \\
\hline$\lambda_{9}$ & & & 0.88 & 8.14 & & & 0.76 & 7.64 \\
\hline ASC $_{\text {socNorm }}$ & & & & & 1.96 & 4.41 & 1.26 & 6.89 \\
\hline$\beta_{\text {CarAvai_SocNorm }}$ & & & & & -0.66 & -2.08 & -0.41 & -2.10 \\
\hline$\beta_{\text {Educ_SocNom }}$ & & & & & 0.14 & 2.88 & 0.08 & 2.79 \\
\hline$\alpha_{4}$ & & & & & 0.30 & 1.34 & -0.06 & -0.56 \\
\hline$\alpha_{5}$ & & & & & -0.07 & -030 & -0.15 & -1.06 \\
\hline$\lambda_{4}$ & & & & & 0.89 & 9.53 & 1.07 & 16.2 \\
\hline$\lambda_{5}$ & & & & & 0.66 & 6.26 & 0.73 & 7.13 \\
\hline
\end{tabular}


Work-related trips are found to reduce the utility for private motorised modes; this is intuitive due to the frequent and routine nature of such trips. The estimate for the trip characteristics (trip frequency) support this argument; increasing the frequency of a trip reduces the utility of private motorised mode.

The age of an individual is observed to have a significant impact on the likelihood to use active modes. Older individuals are less likely to use active modes of transport compared to younger individuals, possibly due to age-related mobility difficulties.

The educational level of individuals was found to have a significant impact on the choice of mode. We observe that highly educated individuals tend to use an active mode of transport more than less educated respondents. The higher the educational qualification of an individual, the more likely they are to choose an active mode of transport. We suggest that individuals in this class tend to be aware of the carbon footprints of transport. This observation is consistent with the finding in Atasoy et al. (2013). Public education or education in schools and higher education institutions on the benefits of active and green travel could bridge this gap and encourage the less-educated individual to adopt active travel modes as the high-educated (Lind et al., 2015).

Table 8 indicates that the ICLV model has higher choice probabilities compared to the base model; the proportion of choice probabilities above 0.5 and 0.9 are $(61 \%)$ and $(7 \%)$ respectively for the ICLV model, these are greater than those for the base model. Tables 10 and 11 present the classification tables and reinforce the results in Table 8. We compare the observed and predicted outcomes of the alternatives together with the percentage of correct prediction. The results show that the ICLV model produces the highest percentage prediction for all three alternatives.

Table 7: Model fit

\begin{tabular}{lcc}
\hline Index & Base Model & ICLV Model \\
\hline \hline Log-Likelihood & -311.81 & -304.47 \\
\hline Adjusted $\rho^{2}$ & 0.254 & \\
\hline
\end{tabular}

Table 8: Percentage of choice probabilities greater than 0.5 and 0.9

\begin{tabular}{lcc}
\hline Threshold & Base Model & ICLV Model \\
\hline \hline $\mathbf{0 . 5}$ & $48 \%$ & $61 \%$ \\
\hline $\mathbf{0 . 9}$ & $4 \%$ & $7 \%$ \\
\hline \hline
\end{tabular}

Table 9: Percentage of predicted corrected

\begin{tabular}{lccc}
\hline & PT & Car & NMT \\
\hline \hline Base Model & $55.3 \%$ & $74.3 \%$ & $55.6 \%$ \\
\hline ICLV Model & $71.1 \%$ & $82.9 \%$ & $63.0 \%$ \\
\hline \hline
\end{tabular}


Table 10: Classification table

\begin{tabular}{lcccc|cccc}
\hline \multirow{2}{*}{ Observed } & \multicolumn{7}{c}{ Base Model } & \multicolumn{4}{c}{ ICLV Model } \\
\cline { 2 - 10 } & PT & Car & NMT & \% Correct & PT & Car & NMT & $\%$ Correct \\
\hline \hline PT & 21 & 8 & 9 & $55.3 \%$ & 27 & 5 & 6 & $71.1 \%$ \\
\hline Car & 5 & 26 & 4 & $74.3 \%$ & 2 & 29 & 4 & $82.9 \%$ \\
\hline NMT & 7 & 5 & 15 & $55.6 \%$ & 8 & 2 & 17 & $63.0 \%$ \\
\hline Market Share & $33 \%$ & $39 \%$ & $28 \%$ & $62 \%$ & $37 \%$ & $36 \%$ & $27 \%$ & $73.0 \%$ \\
\hline
\end{tabular}

Table 11: Time and Cost Elasticities

\begin{tabular}{|c|ccc|c|c|c|}
\hline \multirow{2}{*}{ Model } & \multicolumn{2}{|c|}{ PT } & \multicolumn{2}{c|}{ Car } & NMT \\
\cline { 2 - 7 } & Trip Cost & Travel Time & Trip Cost & Travel Time & Trip Length \\
\hline \hline \multirow{2}{*}{ Base Model } & Cross Elast & 0.272 & 0.259 & 0.358 & 0.224 & \\
\cline { 2 - 8 } & Direct Elast & -0.598 & -0.373 & -0.504 & -0.403 & -2.67 \\
\hline \multirow{2}{*}{ ICLV Model I } & Cross Elast & 0.227 & 0.243 & 0.360 & 0.235 & \\
\cline { 2 - 8 } & Direct Elast & -0.608 & -0.395 & -0.433 & -0.382 & -2.78 \\
\hline \hline
\end{tabular}

The relationship between household income and car availability has been established in the literature (Ben-akiva 1999). A similar relationship is observed in this study; we found that the likelihood of travelling with PT reduces with increasing level of income. Similarly, car availability increases the utility for private motorised modes and the likelihood of travelling by car. These findings are supported by research findings linking household income and car availability (Benakiva, 1999; Dannewald et al., 2008; Kamargianni et al., 2015; Ortuzar et al., 2011; Temme et al., 2008a; Yáñez et al., 2010).

The total walking time for trips involving PT modes is observed to increase the utility for private motorised mode significantly. As the walking time from the trip start point (home) and the walking time from the destination bus stop to the final destination (e.g. office, shop etc.) increases, the likelihood of choosing PT reduces. This effect is significant in both the base model and the ICLV model and supported by related literature (Yáñez et al., 2010).

The results also indicate that the latent attitude "Personal Norm" increases the disutility of private motorised modes. Persons with pro-environmental attitudes and values are more likely to be PT or active travellers than car users. The choice of transport mode is likely to be influenced by individual internalised values and attitudes rather than societal or communal values (perceived social norms). Persons with strong personal convictions on the impact of transport on the environment are likely to be more concerned about the associated externalities and consequently more likely to travel by environmentally friendly modes (i.e. PT and active modes). The results of the ICLV models confirm the finding of the descriptive analysis in Tables 1 and 2 and collaborates with the conclusions in Belgiawan et al. (2016). Both results demonstrate that individuals with high pro-environmental values tend to be sensitive about their travel behaviours. The results also support the finding in Schwartz (1977); the estimates of the models tested suggest that in the absence of personal norms, social norms alone did not add to the predictive power already provided in the base model. Neither did social norms add to the predictive power already provided 
in the model by the personal norm when both variables were incorporated into the ICLV model (Robert B Cialdini et al., 1991).

In summary, it can be deduced from the results that internalised social norms (personal norms) have a significant influence on individual behaviour. Individuals with pro-environmental attitude are likely to travel with sustainable travel modes. This bolsters the opinion that individuals with pro-environmental attitudes may adopt travel behaviour that offset the carbon footprint of their behaviour compared to individuals with anti-environmental attitudes (Jachimowicz et al., 2019). The estimates for personal norms and social norms in the ICLV model confirms the assertion about the effects of personal norms in related and earlier studies (Bamberg et al., 2007; Belgiawan, 2015; Erikssona et al., 2006; Zhang et al., 2016). The results also support the claim that activated norms and pro-environmental behaviour (PEB) influence overt behaviour by inducing a sense of obligations to act (Schwartz, 1977; Cialdini et al., 1991; Bamberg et al., 2007; Zhang et al., 2016; Ferreira \& Wijngaard, 2019).

\subsection{Implications of results}

The findings have some implications for transport. First, individual attitudes should be considered in the development of transport policy and the design of transport systems, specifically, personal norms. Han (2014) suggested that creating awareness of the consequences of behaviour have substantial impact on personal norm. Therefore, we submit that designing policies and schemes to create awareness of the consequences of travel behaviour and encourage the development of strong personal norms could significantly affect decision making, especially when those norms are directed towards transport and the environment.

Second, subconsciously nudging people to develop a preferred behaviour could have a profound impact on travel behaviour when the nudge is directed towards the environmental impact of transport. We believe that Transport campaigns aimed at changing travel behaviour would be more effective if focused on reinforcing and instilling approved social norms into personal norms. Additionally, framing campaign messages in the context of the environment and health could produce a positive result.

Walking is inevitable in every journey. However, the total walking time for PT journeys was found to directly correlates with the utility of private motorised modes. Increasing the density of bus stops within the trip generation and attraction zones would reduce the total walking time for PT trips. This is recommended to minimise the effects of combined walking distance/time on PT ridership.

\subsection{Conclusion and Recommendations}

In this paper, we estimated three ICLV models involving perceptions with respect to societal values and personal values as latent variables to investigate the impact of perceptions and believes on the predicting power of transport mode choice model. The study has confirmed the significance of individual personal norms on behaviour and more specifically on travel mode choice behaviour. The results of the base and the ICLV model developed with the incorporation of social norms and personal norms as latent variables show that the observed modal attributes, trip characteristics and individual socio-demographic variables have a significant effect on travel behaviour. Most importantly, the results demonstrate that personal norm or pro-environmental 
attitudes rather than social norms influence the choice of transport mode. This suggests that travel behaviour is equally influenced by subjective variables (Avineri, 2011). Therefore, incorporating personal norm as a latent variable in the utility functions of choice models could potentially improve the explanatory power of transport mode choice models. The results also suggest that individuals with pro-environmental attitude are likely to travel with sustainable travel modes. Thus, reinforcing the opinion that individuals with pro-environmental values may adopt travel modes with no or minimal carbon footprint (Jachimowicz et al., 2019). The estimates and level of significance of personal norms and social norms in the ICLV models strengthen the argument that activated norms (personal norms) and pro-environmental behaviour (PEB) rather than social norms influence overt behaviour. The perceived symbolism of car was investigated in this study but was not included in the model due to poor identification as a latent variable.

The results reinforce the importance of economic variables in decision-making already established in the literature and provide additional insight into the decision-making process. It is evident from the results that perception and attitudes similarly influence behaviour; this suggest that economic policies and marketing interventions involving transportation choices must not be limited to only economic factors but must consider sociological and psychological factors as well. The data analysed in this study was collected in an urban travel context in a single city in Scotland. Therefore, the generalisability of the results in different travel context is not guaranteed. It is recommended for future research to investigate these latent variables under different travel characteristics.

\section{Acknowledgements}

We acknowledge the Transport Research Institute of Edinburgh Napier University for providing funding support for this study. We also appreciate the anonymous reviewers whose critical and valuable feedback helped to improve the draft of this paper. 


\section{References}

Aczél, R. M. B., \& Markovits-somogyi, R. (2013). Implications of Behavioural Economics for the Transport Sector. 1, 65-69.

Atasoy, B., Glerum, A., \& Bierlaire, M. (2013). Attitudes towards mode choice in Switzerland. DisP-The Planning Review, 49(2), 101-117. https://doi.org/10.1080/02513625.2013.827518

Avineri, E. (2009). Changing travel behaviour: Lessons from "behavioural economics." Transportation Professional, August, 28-29.

Avineri, E. (2011). Applying behavioural economics in the design of travel information systems. UTSG, January, 1-12.

Avineri, E. (2012a). On the use and potential of behavioural economics from the perspective of transport and climate change. Journal of Transport Geography, 24, 512-521. https://doi.org/10.1016/j.jtrangeo.2012.03.003

Avineri, E. (2012b). Understanding Travel Behaviour: Insight from Behavioural Economics and Cognitive Psychology.

Avineri, E., Chatterjee, K., Darnton, A., Goodwin, P., Lyons, G., Musselwhite, C., Pilkington, P., Rayner, G., Tapp, A., Waygood, E. O. D., \& Wiltshire, P. (2009). Individual Behaviour Change: Evidence in transport and public health. November.

Bamberg, S., Hunecke, M., \& Blo, A. (2007a). Social context, personal norms and the use of public transportation: Two field studies. 27, 190-203. https://doi.org/10.1016/j.jenvp.2007.04.001

Bamberg, S., Hunecke, M., \& Blo, A. (2007b). Social context, personal norms and the use of public transportation: Two field studies. Environmental Psychology, 27, 190-203. https://doi.org/10.1016/j.jenvp.2007.04.001

Belgiawan, P.F., Schmöcker, J.-D. J.-D., Abou-Zeid, M., Walker, J., \& Fuji, S. (2015). The Role of Expectation of Others on Students ' Likelihood to Buy a Car. 94th Annual Meeting of the Transportation Research Board, January.

Belgiawan, Prawira F., Schmöcker, J. D., \& Fujii, S. (2016). Understanding car ownership motivations among Indonesian students. International Journal of Sustainable Transportation, 10(4), 295-307. https://doi.org/10.1080/15568318.2014.921846

Belgiawan, Prawira Fajarindra. (2015). Role of Attitudes and Norms for Students Car Ownership Intention. KYOTO UNIVERSITY.

Ben-akiva, M. (1999). Extended Framework for Modeling Choice Behavior. 3, 187-203.

Ben-akiva, M., \& Bierlaire, M. (1999). Discrete Choice Methods and their Applications to Short Term Travel Decisions. In Discrete Choice Methods.

Ben-akiva, M., \& Boccara, B. (1995). Discrete choice models with latent choice sets. 12, 9-24.

Ben-Akiva, ME, \& Lerman, S. (1985). Discrete choice analysis: theory and application to travel demand. https://books.google.co.uk/books?hl=en\&lr=\&id=oLC6ZYPs9UoC\&oi=fnd\&pg=PR11\&ots= nMeyl07kDa\&sig=C32Pg_BPqA3hC_efNNI2tjjQDIw

Ben-Akiva, Moshe, \& Boccara, B. (1995). Discrete choice models with latent choice sets. 12, 924.

Ben-Akiva, Moshe, Boersch-supan, A., Mcfadden, D., Train, K., Walker, J., Bhat, C., Bierlaire, 
M., Bolduc, D., Boersch-supan, A., Brownstone, D., Bunch, D. S., Daly, A., De Palma, A., Gopinath, D., Karlstrom, A., \& Munizaga, M. A. (2002). Hybrid Choice Models: Progress and Challenges. Marketing Letters, 13(3), 163-175.

https://doi.org/10.1023/A:1020254301302

Ben-Akiva, Moshe, Walker, J., Bernardino, A. T., Gopinath, D. A., Morikawa, T., \& Polydoropoulou, A. (1999). Integration of Choice and Latent Variable Models. Proceedings of 8th International Conference on Travel Behavior, 1.

Bierlaire, M. (2018a). Mode choice in Switzerland ( Optima ). 1-8.

Bierlaire, M. (2018b). PandasBiogeme : a short introduction.

Burke, M. A., \& Young, P. H. (2011). Social Norms. In I. J. Benhabib, A. Bisin, \& M. O. Jackson (Eds.), Handbook of Social Economics (pp. 311-338).

Cialdini, R. B., Wosinska, W., Barrett, D. W., Butner, J., \& Gornik-Durose, M. (1999). Compliance with a Request in Two Cultures: The Differential Influence of Social Proof and Commitment/Consistency on Collectivists and Individualists. Personality and Social Psychology Bulletin, 25(10), 1242-1253. https://doi.org/10.1177/0146167299258006

Cialdini, R.B. (2007). Influence: The Psychology of Persuasion (Revised). HarperBusiness.

Cialdini, Robert B, Kallgren, C. A., \& Reno, R. R. (1991). A focus theory of normative conduct. A theoretical refinement and reevaluation of the role of norms in human behavior. Advances in Experimental Social Psychology, 24(20), 201-234. https://doi.org/10.1016/S00652601(08)60330-5

Cronbach, L. J. (1951). Coefficient alpha and the internal structure of tests. Psychometrikatrika, 16(3).

Dannewald, T., Paulssen, M., Temme, D., \& Walker, J. (2008). Hybrid choice models estimation using canned SEM software. Flexible Marketing in an Unpredictable World. Proceedings of the 36th EMAC Conference, Sfb 649.

DellaVigna, S. (2009). Psychology and economics. Evidence from the field. Journal of Economic Literature, 47, 315-372.

Edinburgh City Council. (2016). Demographic Factsheet.

Erikssona, L., Garvilla, J., \& Nordlunda, A. M. (2006). Acceptability of transport demand management measures: The importance of problem awareness, personal norm, freedom, and fairness. Journal of Environmental Psychology, 26, 15-26.

Ferreira, M., \& Wijngaard, R. van den. (2019). Pro-Environmental Behaviour: We Care Because Others Do. In In A. Samson (Ed.), The Behavioral Economics Guide 2019 (with an Introduction by Uri Gneezy) (pp. 122-130).

Goodwin, P., \& Dender, K. Van. (2013). 'Peak Car'- Themes and Issues. Transport Reviews, 33(3), 243-254. https://doi.org/10.1080/01441647.2013.804133

Halonen, E. (2020). Does "Irrationality" Travel? Why Applied Behavioural Science Needs to Consider Cultural Context. January 15. https://www.behavioraleconomics.com/doesirrationality-travel-why-applied-behavioural-science-needs-to-consider-cultural-context/

Han, H. (2014). The norm activation model and theory-broadening: Individuals' decision-making on environmentally-responsible convention attendance. Journal of Environmental Psychology, 40(2014), 462-471. https://doi.org/10.1016/j.jenvp.2014.10.006

Hirshleifer, D. (1993). The Blind leading the blind: social influence, fads, and informational cascades. The New Economics of Human Behaviour, 188-215. 
Hiselius, L. W., \& Rosqvist, L. S. (2016). Mobility Management campaigns as part of the transition towards changing social norms on sustainable travel behavior. In Journal of Cleaner Production (Vol. 123, pp. 34-41). https://doi.org/10.1016/j.jclepro.2015.08.055

Johansson, M. V., \& Heldt, T. (2006). The effects of attitudes and personality traits on mode choice. Transportation Research Part A, 40, 507-525.

Kamargianni, M., \& Amalia, M. B. (2014). Incorporating social interaction into hybrid choice models. Transportation, 41, 1263-1285. https://doi.org/10.1007/s11116-014-9550-5

Kamargianni, M., Dubey, S., Polydoropoulou, A., \& Bhat, C. (2015). Investigating the subjective and objective factors influencing teenagers' school travel mode choice - An integrated choice and latent variable model. Transportation Research Part A: Policy and Practice.

Kline, R. B. (2011). Principles and practice of structural equation modeling. In Structural Equation Modeling (Vol. 156). https://doi.org/10.1038/156278a0

Klöckner, C. A., \& Blöbaum, A. (2010). A comprehensive action determination model: Toward a broader understanding of ecological behaviour using the example of travel mode choice. Journal of Environmental Psychology, 30(4), 574-586.

https://doi.org/10.1016/j.jenvp.2010.03.001

Limtanakool, N., Dijst, M., \& Schwanen, T. (2006). The influence of socioeconomic characteristics, land use and travel time considerations on mode choice for medium- and longer-distance trips. Journal of Transport Geography, 14(5), 327-341. https://doi.org/10.1016/j.jtrangeo.2005.06.004

Lind, H. B., Nordfjærn, T., Jørgensen, S. H., \& Rundmo, T. (2015). The value-belief-norm theory, personal norms and sustainable travel mode choice in urban areas. Journal of Environmental Psychology, 44, 119-125. https://doi.org/10.1016/j.jenvp.2015.06.001

Liu, C., Vlaev, I., Fang, C., Denrell, J., \& Chater, N. (2017). Strategizing with Biases: Making Better Decisions Using the Mindspace Approach. California Management Review, 59(3), 135-161. https://doi.org/10.1177/0008125617707973

Long, J., Harré, N., \& Atkinson, Q. D. (2015). Social clustering in high school transport choices. Journal of Environmental Psychology, 41, 155-165. https://doi.org/10.1016/j.jenvp.2015.01.001

Mackie, G., Moneti, F., Shakya, H., \& Denny, E. (2015). What are social norms? How are they measured? In What are Social Norms? (Issue July). http://www.polisci.ucsd.edu/ gmackie/

Manski, F. C. (1973). The analysis of qualitative choice. [Massachusetts Institute of Technology]. http://dspace.mit.edu/handle/1721.1/13927

Metcalfe, R., \& Dolan, P. (2012). Behavioural economics and its implications for transport. Journal of Transport Geography, 24, 503-511. https://doi.org/10.1016/j.jtrangeo.2012.01.019

Millard-Ball, A., \& Schipper, L. (2011). Are we reaching peak travel? trends in passenger transport in eight industrialized countries. Transport Reviews, 31(3), 357-378. https://doi.org/10.1080/01441647.2010.518291

Muthén, L. K., \& Muthén, B. O. (2010). Mplus User's Guide (Muthén \& Muthén (ed.); Sixth Edit).

National Records of Scotland. (2018). Population Estimates Time Series Data. Mid-Year Population Estimates.

Ortuzar, J. de D., Willumsen, L. G., Ortúzar, J. de D., \& Willumsen, L. G. (2011). Modelling Transport (Fourth). John Wiley \& Son. https://doi.org/10.1002/9781119993308 
Riggs, W. (2016). Testing Social Norms As an Incentive to Active Transportation Behavior. Journal of Transport \& Health, 3(2), S30. https://doi.org/10.1016/j.jth.2016.05.074

Riggs, W. (2017). Painting the fence: Social norms as economic incentives to non-automotive travel behavior. Travel Behaviour and Society, 7, 26-33.

https://doi.org/10.1016/j.tbs.2016.11.004

Riley, E. (2020). Edinburgh is named worst UK city for traffic misery for THIRD year in row Daily Mail Online. In The High CONGESTION Road! Edinburgh is named worst UK city for traffic misery for THIRD year in row - while Bengaluru is branded world's bumper-tobumper capital. https://www.dailymail.co.uk/news/article-7942697/Edinburgh-named-worstUK-city-traffic-misery-year-row.html

Schroeder, D. A., Jensen, T. D., Reed, A. J., Sullivan, D. K., \& Schwab, M. (1983). The actions of others as determinants of behavior in social trap situations. Journal of Experimental Social Psychology, 19(6), 522-539. https://doi.org/10.1016/0022-1031(83)90014-8

Schwartz, S. H. (1977a). Normative influences on altruism. Advances in Experimental Social Psychology, 10, 221-279.

Schwartz, S. H. (1977b). Normative influences on altruism. Advances in Experimental Social Psychology, 10(January 1977), 221-279.

Schwartz, S. H. (1977c). Normative Influences on Altruism. January 1977.

Scottish Government. (2018). Scottish Household Survey: Scotland's People Local Authority Tables - 2017.

Shan, R., \& John, C. (2015, March). Edinburgh third most congested city in UK. Scotsman, 30.

Simon, H. A. (1955). A Behavioral Model of Rational Choice Author ( $s$ ): Herbert A . Simon Published by: Oxford University Press Stable URL : http://www.jstor.org/stable/1884852. 69(1), 99-118.

Simon, H. A. (1982). Models of bounded rationality (Vol. 2). In Behavioral economics and business organization. MA:MIT Press.

Temme, D., Paulssen, M., Dannewald, T., Timme, D., Marcel, P., \& Till, D. (Infas T. F. (2008a). Incorporating Latent Variables into Discrete Choice Models- A Simultaneous Estimation Approach Using SEM Software. Business Research, 1(2), 220-237. https://doi.org/10.1007/BF03343535

Temme, D., Paulssen, M., Dannewald, T., Timme, D., Marcel, P., \& Till, D. (Infas T. F. (2008b). Incorporating Latent Variables into Discrete Choice Models - A Simultaneous Estimation Approach Using SEM Software. Business Research, 1(2), 220-237. https://doi.org/10.1007/BF03343535

TomTom International BV. (2016). TomTom Traffic Index: Measuring Congestion Worldwide. Traffic Congestion Statistics for Edinburgh Based on TomTom's Historical Database for 2016. https://www.tomtom.com/en_gb/trafficindex/city/edinburgh

Transport Scotland. (2015). Transport and Travel in Scotland 2014: A National Statistics Publication for Scotland. August.

Transport Scotland. (2017). A National Statistics Publication for Scotland: Scottish Transport Statistics (Issue 2017 edition).

Transport Scotland. (2018a). Transport and Travel in Scotland 2017 (Issue September).

Transport Scotland. (2018b). Transport and Travel in Scotland 2017 - Scottish Household Survey Local Authority results. 
https://www2.gov.scot/Topics/Statistics/16002/LATables2017/2017Excel

Yáñez, M. F., Raveau, S., \& Ortúzar, J. de D. (2010). Inclusion of latent variables in Mixed Logit models: Modelling and forecasting. Transportation Research Part A: Policy and Practice, 44(9), 744-753. https://doi.org/10.1016/j.tra.2010.07.007

Zhang, D., Schmöcker, J.-D., Fujii, S., \& Yang, X. (2016). Social norms and public transport usage: empirical study from Shanghai. Transportation, 43(5), 869-888. 